\title{
SISTEM PAKAR DIAGNOSA KERUSAKAN MAINBOARD KOMPUTER
}

\section{EXPERT SYSTEM DIAGNOSIS OF COMPUTER MAINBOARD FAILURE}

\author{
Rizky Ambarita \\ Fakultas Teknik, Program Studi Teknik Informatika \\ Universitas Muhammadiyah Maluku Utara \\ rizkyambarita14@gmail.com
}

\begin{abstract}
Abstrak
Mainboard komputer adalah sebuah perangkat keras yang terdapat pada komputer dan tempat di mana semua perangkat keras yang lain dipasangkan. Oleh karena itu, kerusakan yang terdapat pada mainboard sangat berpengaruh pada seluruh kinerja komputer. Banyak berbagai permasalahan yang sering dikeluhkan oleh para pengguna komputer, terkadang mereka memerlukan teknisi atau pakar untuk medeteksi kerusakan tersebut. Sebagian dari pengguna komputer menganggap bahwa pekerjaan penelusuran kesalahan atau kerusakan pada komputer terlalu rumit untuk dilakukan sehingga memerlukan pakar atau teknisi dalam menangani masalah kerusakan pada mainboard tersebut. Penilitian ini menggunakan model pencarian kerusakan yaitu metode pelacakan kedepan (Forward chaining), bahasa pemograman yang digunakan adalah $P H P$ dengan database $M y S Q L$. Dengan adanya sistem ini diharapkan dapat memberikan kemudahan pada pengguna komputer untuk mengetahui gejala-gejala kerusakan yang terjadi pada Mainboard Komputer yang dapat diakses pada sistem dimana saja.
\end{abstract}

\section{Kata Kunci : Sistem Pakar, Diagnosa Kerusakan, Mainboard Komputer}

\section{Abstract}

Mainboard computer is hardware contained on the computer and the place where all the other hardware in pairs, therefore the damage found on the mainboard is very influential on all computer performance. Many of the problems that computer users often complain about, sometimes they need technicians or experts to detect such damage. Some of the computer users assume that the work of error tracking or damage to the computer is too complicated to do so requires an expert or technician to deal with the damage problem on the mainboard. This research uses damage search model that is forward tracking method (Forward chaining), the programming language used is PHP with MySql database. With the existence of this system is expected to provide convenience to computer user to know the symptoms of damage that happened on Mainboard Computer that can be accessed On the system anywhere.

\section{Keyword: Expert System, Diagnosis Computer, Mainboard Failure}

\section{PENDAHULUAN}

Mainboard komputer adalah sebuah perangkat keras yang terdapat pada komputer dan tempat di mana semua perangkat keras yang lain dipasangkan.
Banyak berbagai permasalahan yang sering dikeluhkan oleh para pengguna komputer, terkadang mereka langsung membawa komputer ke teknisi tanpa merasa perlu untuk mengetahui apa yang sebenarnya terjadi pada komputer mereka 
tersebut. Sebagian dari pengguna komputer menganggap bahwa pekerjaan penelusuran kesalahan atau kerusakan pada komputer terlalu rumit untuk dilakukan sehingga memerlukan pakar atau teknisi dalam menangani masalah kerusakan pada mainboard tersebut.

Sistem pakar adalah sebuah perangkat lunak komputer yang memiliki basis pengetahuan untuk domain tertentu dan menggunakan penalaran inferensi menyerupai seorang pakar dalam memecahkan masalah (Farid, 1994). Basis pengetahuan yang diperoleh diambil dari pengetahuan seorang pakar maupun teoriteori yang ada pada bidang secara spesifik saja. Adanya sistem pakar dapat memberikan solusi alternatif kepada pengguna untuk mengetahui informasiinformasi yang diperlukan seperti seorang pakar dalam bidang tertentu.

Berdasarkan masalah tersebut, maka perlu adanya suatu perangkat lunak Sistem Pakar Diagnosa Kerusakan Mainboard Komputer. Sistem yang dirancang menggunakan model pencarian kerusakan yaitu metode pelacakan kedepan (Forward chaining), bahasa pemograman yang digunakan adalah PHP dengan database MySql. Dengan adanya sistem ini diharapkan dapat memberikan kemudahan pada pengguna komputer untuk mengetahui gejala-gejala kerusakan yang terjadi pada mainboard komputer yang dapat diakses pada sistem dimana saja.

\section{Rumusan Masalah}

Masalah dalam penilitian ini adalah bagaimana membuat suatu "Sistem Pakar Diagnosa Kerusakan Mainboard Komputer" untuk memberikan informasi kepada pengguna (user) komputer tentang kerusakan pada mainboard komputer?
Berdasarkan rumusan masalah, penilitian ini bertujuan untuk merancang sebuah aplikasi sistem pakar yang diharapkan dapat memberikan kemudahan pada pengguna komputer untuk mengetahui gejala-gejala kerusakan yang terjadi pada mainboard komputer yang dapat diakses pada sistem dimana saja.

\section{LANDASAN TEORI \\ Defenisi Sistem}

Sistem yaitu yang menekankan pada prosedurnya dan yang menekankan pada komponen atau elemennya. Sistem dapat diartikan sebagai kumpulan dari beberapa komponen yang saling berhubungan satu dengan yang lainnya membentuk satu kesatuan untuk mencapai tujuan tertentu (Jogiyanto, 2009:34).

\section{Sistem Informasi}

Suatu sistem yang dibuat oleh manusia yang terdiri dari komponenkomponen dalam organisasi untuk mencapai suatu tujuan yaitu menyajikan informasi (Ladjamudin, 2005:13)

Menurut Bonnie Soeherman dan Marion Pinontoan, (2008:5), sistem informasi merupakan serangkaian komponen berupa manusia, prosedur, data, dan teknologi (seperti komputer) yang digunakan untuk melakukan sebuah proses untuk pengambilan keputusan guna penunjang keberhasilan bagi setiap organisasi (dalam pencapaian tujuan).

\section{MySQL}

MySQL adalah salah satu jenis database server yang sangat populer, hal ini disebabkan karena MySQL menggunakan SQL sebagai bahasa dasar untuk mengakses databasenya. (Kadir, 2008:62). 


\section{Basis Data}

Basis dapat diartikan sebagai markas atau gudang, tempat bersarang atau berkumpul. Sedangkan data merupakan representasi fakta dunia nyata yang mewakili suatu objek seperti manusia (pegawai, siswa, pembeli, pelanggan), barang, hewan peristiwa, konsep, keadaan, dan sebagainya yang direkam dalam bentuk angka, huruf, simbol, teks, gambar, bunyi, atau kombinasinya. Basis data (database) merupakan kumpulan data yang saling berhubungan (punya relasi). Relasi biasanya ditunjukkan dengan kunci (key) dari tiap file yang ada. Dalam suatu file terdapat record-recordyang sejenis, sama besar, sama bentuk, yang merupakan satu kumpulan entitas yang seragam. Satu record terdiri dari field-field yang saling berhubungan dan menunjukkan dalam satu pengertian yang lengkap dalam satu record (Yakub, 2012)

\section{Forward Chaining}

Menurut Arhami (2005:115) Forward chaining disebut juga penalaran dari bawah ke atas karena penalaran dari fakta pada level bawah menuju konklusi pada level atas didasarkan pada fakta. Penalaran dari bawah ke atas dalam suatu sistem pakar dapat disamakan untuk pemgrograman konvensional dari bawah ke atas. Fakta merupakan satuan dasar dari paradigma berbasis pengetahuan karena mereka tidak dapat diuraikan ke dalam satuan paling kecil yang mempunyai makna.

Pada metode forward chaining ini ada dua cara yang dapat dilakukan untuk melakukan pencarian, yaitu, Ignizio Dalam (Kusrini, 2006)

1. Dengan memasukan semua data yang tersedia ke dalam sistem pakar pada satu kesempatan dalam sesi konsultasi.
Cara ini banyak berguna pada sistem pakar yang termasuk dalam proses terautomatisasi dan menerima data langsung dari komputer yang menyimpan database, atau dari satu set sensor.

2. Dengan hanya memberikan elemen spesifik dari data yang diperoleh selama sesi konsultasi kepada sistem pakar. Cara ini mengurangi jumlah data yang diminta, sehingganya data yang diminta hanyalah data-data yang benar-benar dibutuhkan oleh sistem pakar dalam mengambil keputusan.

\section{Mainboard Komputer}

Motherboard atau mainboard adalah papan utama berupa PCB (Printed Circuit Board) yang memiliki chip bios (program penggerak), jalur-jalur dan konektor sebagai penghubung akses masing-masing perangkat. Karena Motherboard lah semua komponen PC akan disatukan. Motherboard menghubungkan semua peralatan komputer dan membuatnya bekerja sama sehingga komputer berjalan dengan lancer.

\section{Chipset Mainboard}

Chipset Northbridge mempunyai peranan yang penting terhadap beberapa komponen pada mainboard. Komponen ini bekerja sama dengan graphics card untuk menampilkan gambar pada monitor. Selain itu Northbridge juga bertanggung jawab terhadap PCI slots, USB, Sound chip, LAN chip, the BIOS ROM chip.

Chipset Southbridge mempunyai tugas untuk mengontrol perangkatperangkat yang masuk ke mainboard melalui USB (Universal Serial Bus), IDE Hardisk, battery Cmos.

\section{Data Flow Diagram}


Data Flow Diagram (DFD) merupakan alat untuk membuat diagram yang serbaguna. Data flow diagram terdiri dari notasi penyimpanan data (data store), proses (process), aliran data (flowdata) dan sumber masukan (entity), (Yakub,2012).

\section{Entity Relationship Diagram (ERD)}

Entity relationship diagram (ERD) untuk mendokumentasikan data perusahaan dengan mengidentifikasi jenis entitas (entity) dan hubungannya. ERD merupakan suatu model jaringan yang menggunakan susunan data yang disimpan pada sistem secara abstrak. ERD juga menggambarkan hubungan antara suatu entitas yang memiliki sejumlah atribut dengan entitas yang lain dalam suatu sistem yang terintegrasi. ERD digunakan oleh perancangan sistem untuk memodelkan data yang nantinya akan dikembakan menjadi basis data (database). ERD ini juga merupakan model konseptual yang dapat mendeskripsikan hubungan antara file yang digunakan untuk memodelkan struktur data serta hubungan atar data (Yakub, 2012).

\section{METODE PENELITIAN}

Dalam pembuatan sistem ini penulis mencoba untuk melakukan eksperimen dalam pengembangan sistem dari penelusuran wawancara dan observasi pada teknisi tentang kerusakan komputer dengan berbagai sumber yang pakar yaitu dibidangnya menjadi sistem pakar untuk kerusakan pada mainboard komputer dengan metode forward chaining. Penerapan sistem pakar yang berbasis web merupakan solusi untuk meminimalisasi keterbatasan para pengguna untuk mengetahui kerusakan dan gejala-gejala kerusakan yang terjadi pada mainboard komputer yang dapat diakses pada sistem dimana saja.

\section{Bahan dan Alat Penilitian}

Perangkat keras dan perangkat lunak yang dibutuhkan untuk merancang aplikasi ini sebagai berikut :

1. Perangkat Keras (Hardware)

Processor Intel Pentium (R) P6100 @ $2.00 \mathrm{GHz}$

Hardisk 240 GB

RAM (Random Access Memory) 1 GB

Monitor 14 Inch

Keyboard dan Mouse

Modem

2. Perangkat Lunak (Sofware)

PHPMy Admin

Xampp

Mozilla Firefox

\section{PERANCANGAN SISTEM \\ Perancangan Tabel}

Tabel 1. Tabel Admin

\begin{tabular}{|l|l|l|l|}
\hline Nama_Field & $\begin{array}{c}\text { Type } \\
\text { Data }\end{array}$ & Ukuran & Keterangan \\
\hline id_admin & Int & 5 & Id Admin \\
\hline Username & Varchar & 50 & $\begin{array}{l}\text { Nama } \\
\text { Admin }\end{array}$ \\
\hline Password & Varchar & 50 & Password \\
\hline
\end{tabular}

Tabel 2. Tabel Gejala

\begin{tabular}{|l|l|l|l|}
\hline Nama_Field & $\begin{array}{l}\text { Type } \\
\text { Data }\end{array}$ & Ukuran & Keterangan \\
\hline kd_gejala & Char & 3 & Kode Gejala \\
\hline Nama_gejala & text & & $\begin{array}{l}\text { Nama } \\
\text { Gejala }\end{array}$ \\
\hline
\end{tabular}

Tabel 3. Tabel Kerusakan

\begin{tabular}{|l|l|l|l|}
\hline Nama_Field & $\begin{array}{l}\text { Type } \\
\text { Data }\end{array}$ & Ukuran & Keterangan \\
\hline kd_kerusakan & Char & 3 & $\begin{array}{l}\text { Kode } \\
\text { Kerusakan }\end{array}$ \\
\hline kd_penyebab & Varchar & 50 & $\begin{array}{l}\text { Kode } \\
\text { Penyebab }\end{array}$ \\
\hline kd_solusi & Char & 3 & Kode Solusi \\
\hline Kerusakan & Varchar & 50 & Kerusakan \\
\hline Kerusakan_img & Varchar & 100 & Gambar \\
\hline
\end{tabular}


Tabel 4. Tabel Pakar

\begin{tabular}{|l|l|l|l|}
\hline Nama_Field & $\begin{array}{l}\text { Type } \\
\text { Data }\end{array}$ & Ukuran & Keterangan \\
\hline Id_pakar & Int & 5 & Id pakar \\
\hline Id_admin & Int & 11 & Id admin \\
\hline Kd_kerusakan & Char & 3 & $\begin{array}{l}\text { Kode } \\
\text { kerusakan }\end{array}$ \\
\hline Kd_gejala & Varchar & 100 & Kode gejala \\
\hline
\end{tabular}

Tabel 5. Tabel Pengunjung

\begin{tabular}{|l|l|l|l|}
\hline Nama_Field & $\begin{array}{l}\text { Type } \\
\text { Data }\end{array}$ & Ukuran & Keterangan \\
\hline Id_pengunjung & Int & 5 & $\begin{array}{l}\text { Id } \\
\text { Pengunjung }\end{array}$ \\
\hline Kd_kerusakan & Varchar & 50 & $\begin{array}{l}\text { Kode } \\
\text { Kerusakan }\end{array}$ \\
\hline Kd_gejala & Varchar & 50 & Kode Gejala \\
\hline Nama_lengkap & Varchar & 50 & $\begin{array}{l}\text { Nama } \\
\text { Lengkap }\end{array}$ \\
\hline Alamat & Text & & Alamat \\
\hline
\end{tabular}

Tabel 6. Tabel Penyebab

\begin{tabular}{|l|l|l|l|}
\hline Nama_Field & $\begin{array}{l}\text { Type } \\
\text { Data }\end{array}$ & Ukuran & Keterangan \\
\hline Kd_penyebab & Char & 3 & $\begin{array}{l}\text { Kode } \\
\text { Penyebab }\end{array}$ \\
\hline Penyebab & Text & & penyebab \\
\hline
\end{tabular}

Tabel 7. Tabel Solusi

\begin{tabular}{|l|l|l|l|}
\hline Nama_Field & $\begin{array}{l}\text { Type } \\
\text { Data }\end{array}$ & Ukuran & Keterangan \\
\hline Kd_solusi & Char & 3 & Kode Solusi \\
\hline Solusi & Text & & Solusi \\
\hline
\end{tabular}

\section{Diagram Konteks}

Diagram Konteks merupakan tampilan rancangan desain sistem secara umum, berikut merupakan tampilan rancangan diagram konteks yang disajikan dalam gambar sebagai berikut:

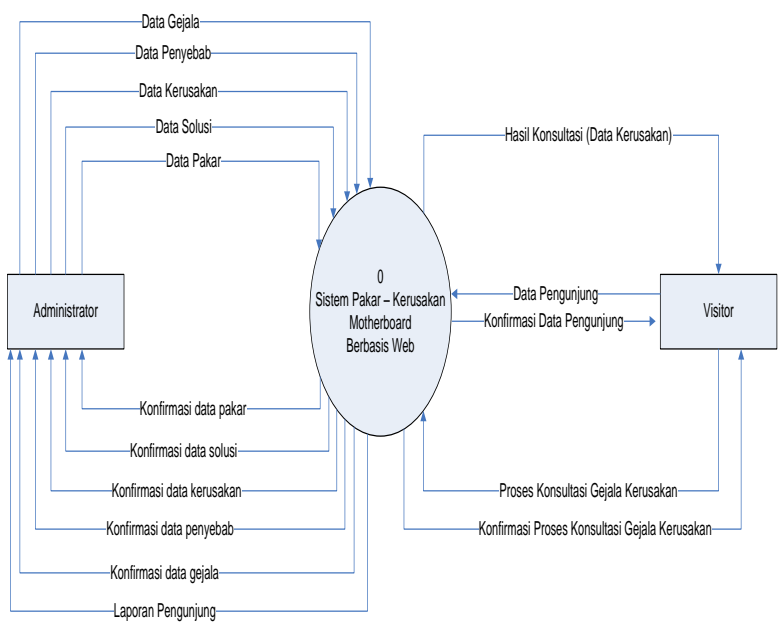

Gambar 1 : Diagram Konteks Sistem

\section{DFD Level 1}

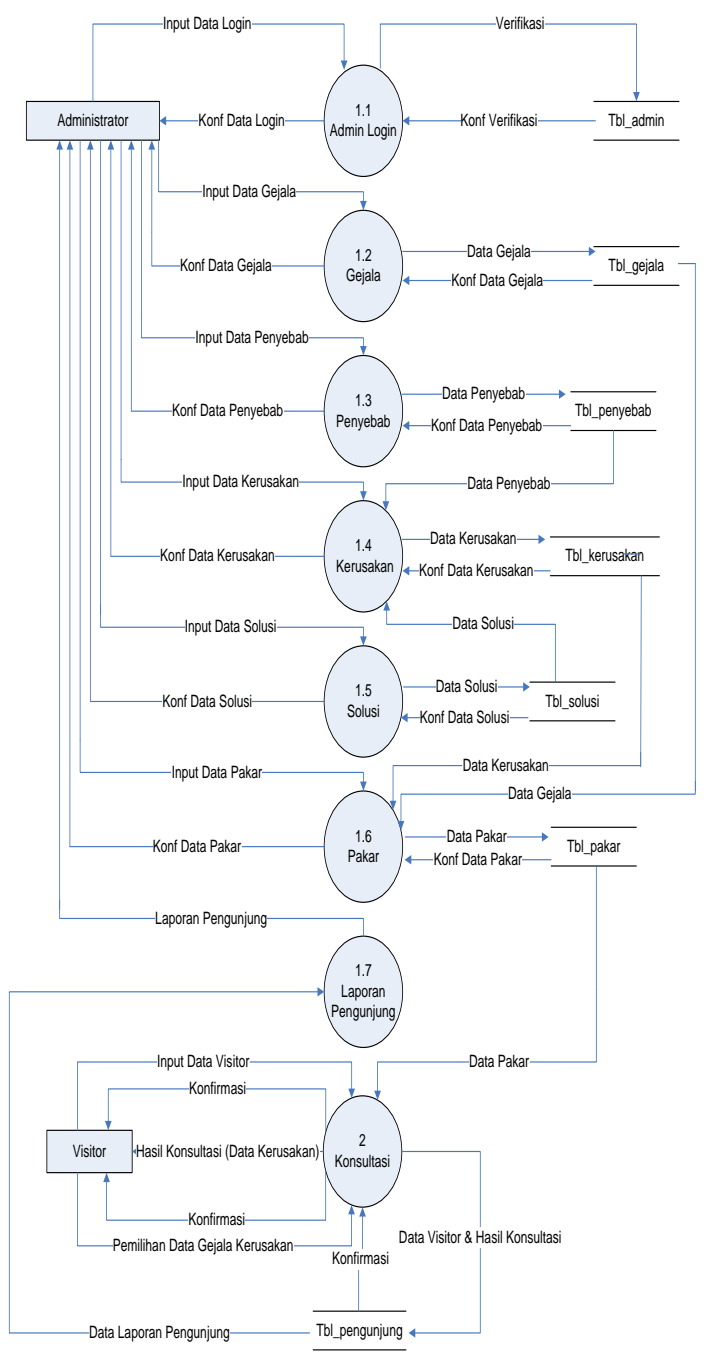

Gambar 2 : DFD Level 1 Sistem 


\section{ERD (entity relationship diagram)}

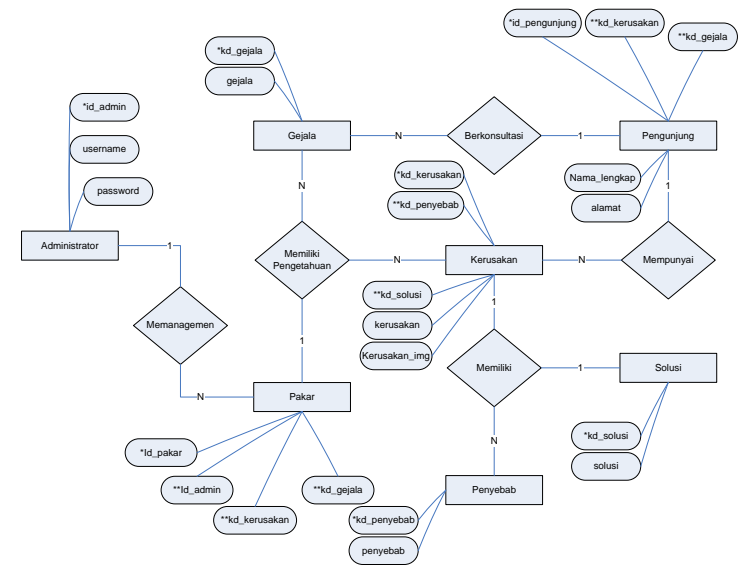

Gambar 3: ERD Notasi

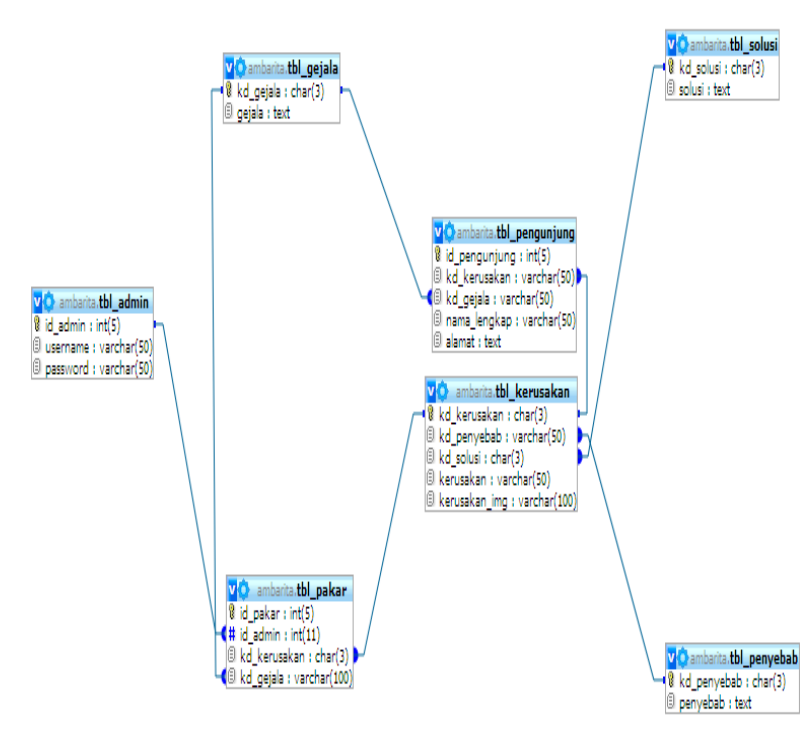

Gambar 4: ERD Relasi

\section{IMPLEMENTASI SISTEM \\ Form Login}

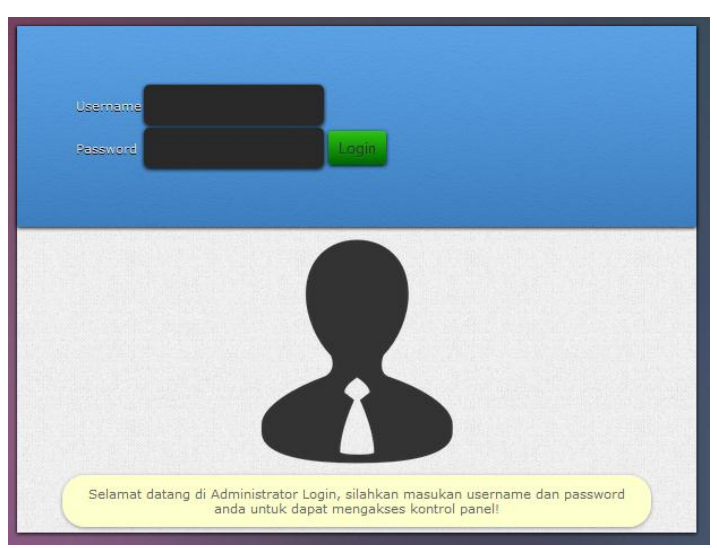

Gambar 5 : Form Login

\section{Form Admin}

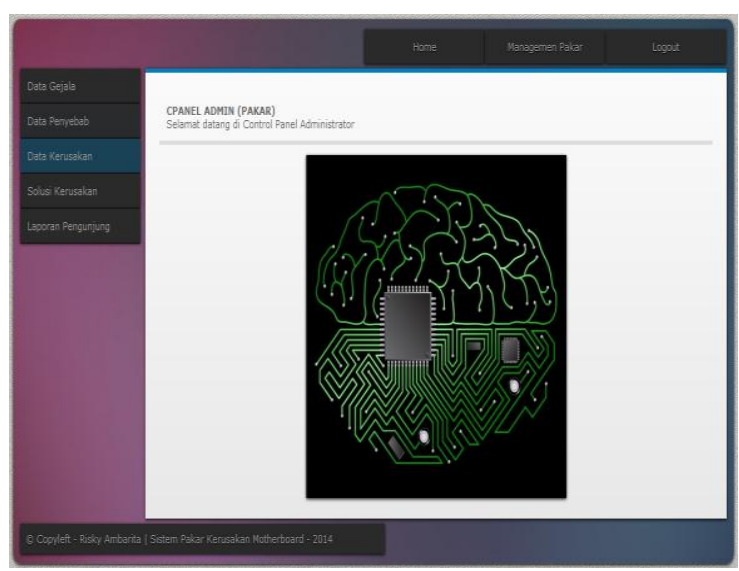

Gambar 6 : Form Admin

\section{Form Management Pakar}

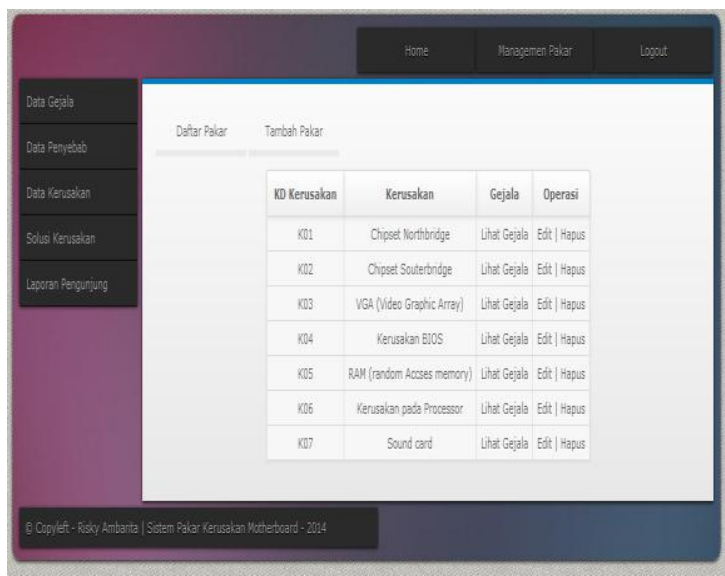

Gambar 7 : Form Management Pakar

\section{Form menu utama user}

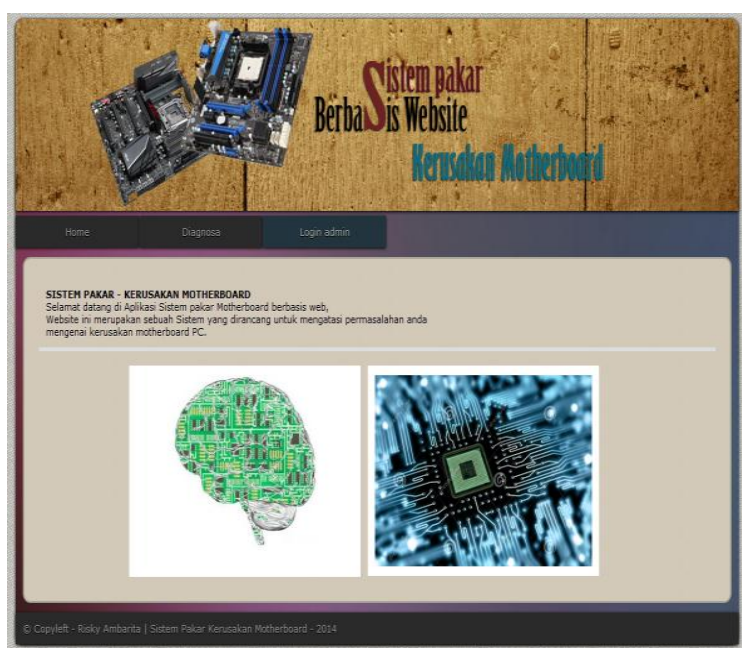

Gambar 8 : Form menu utama user 


\section{Form Diagnosa}

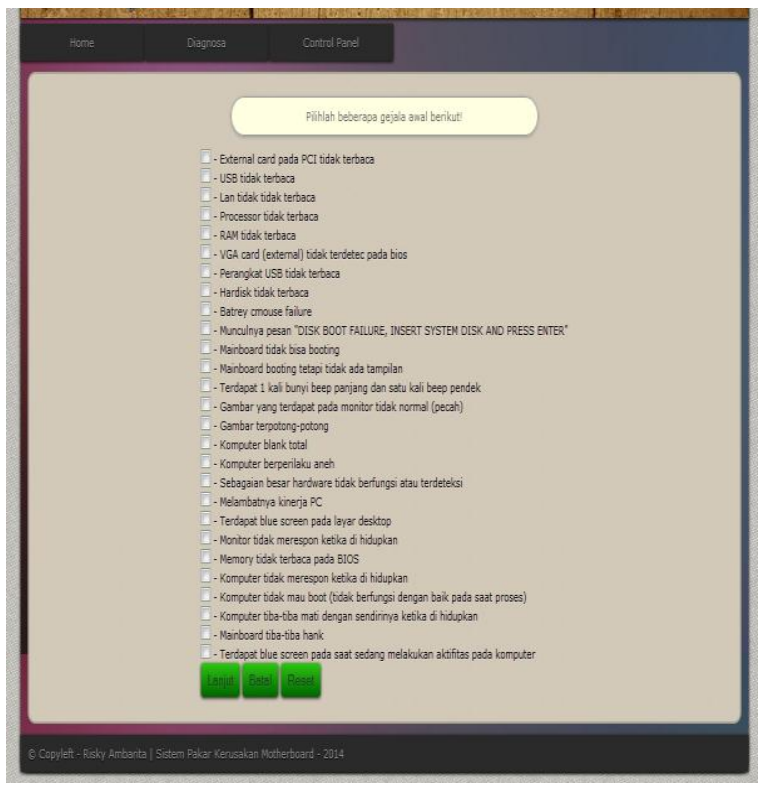

Gambar 9 : Form Diagnosa

\section{Form Hasil Diagnosa}

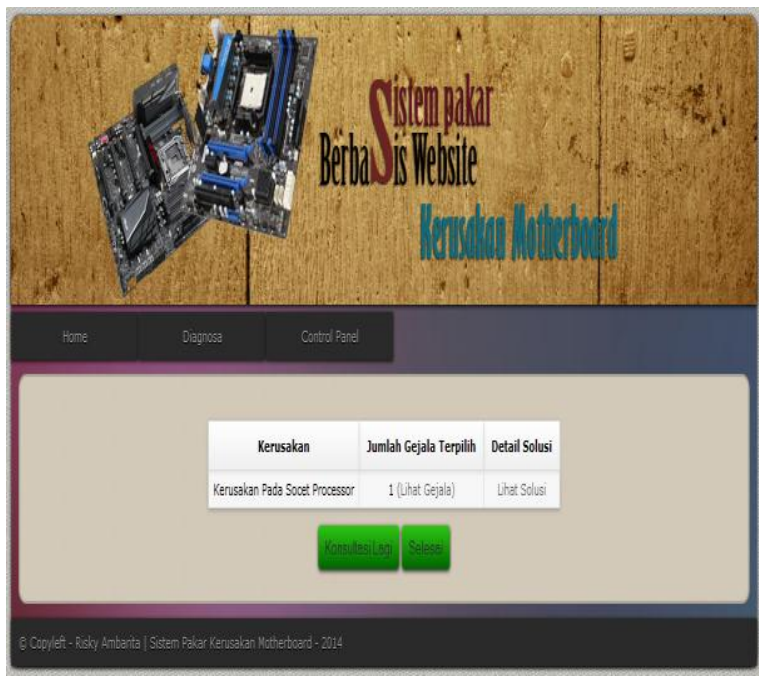

Gambar 10 : Form Hasil Diagnosa

\section{KESIMPULAN}

Hasil Perancangan Sistem Pakar Diagnosa Kerusakan Mainboard Komputer disimpulkan sebagai berikut: 1) Dengan adanya sistem pakar yang dibangun berbasis website maka untuk melakukan konsultasi dan pertanyaan seputar kerusakan umum pada mainboard komputer lebih mudah karena dapat diakses dimana saja selama layanan internet digunakan.; 2) Sistem pakar berbasis website yang dibangun ini diharapkan dapat memberikan kemudahan bagi pengguna komputer yang sedang mengalami masalah seputar manboard computer.

Berdasarkan kesimpulan di atas, maka diajukan saran sebagai berikut.: 1) Untuk pengembangan mendatang hasil diagnosa ditampilkan solusi dengan menyajikan bentuk gambar lengkap pada alat tersebut: 2) Sistem yang dibangun diharapkan tidak hanya sebatas pengelolaan konsultasi kerusakan mainboard komputer yang sering dialami para pegguna komputer tetapi juga pengelolaan terkait informasi serta artikel-artikel yang berhubungan dengan komputer secara umum yang sering di alami oleh para pengguna (user) computer.

\section{DAFTAR PUSTAKA}

Farid Azis, 1994, Pemrograman Sistem Pakar, Elex Media Komputindo Jakarta.

Al-Bahra bin Ladjamudin, 2005, Analisis Dan Desain Sistem Informasi, Graha Ilmu Yogyakarta.

Arhami, Muhammad. 2005. Konsep Dasar Sistem Pakar. Yogyakarta: Andi Offset.

Kusrini, Sistem Pakar Teori dan Aplikasi, Yogjakarta: Andi 2006

Ramdani Nazaruddin, 2005, "Komputer

Dan Trouble Shooting”, Informatika, Bandung

Soherman Bonnie \& Pinontoan Marion. 2008. Designing Information System. Elex Media Komputindo.Jakarta.

Dreamweaver, Jogyakarta, Gava Media: 2008

Kusrini. 2008. Aplikasi Sistem Pakar. Yogyakarta: Andi Offset.

Jogiyanto. 2009. Sistem Teknologi Informasi. Andi. Yogyakarta. 
Agus Sale, 2012, Mainboard Repair, Qbook Media Grup,Yogyakarta

Yakub,2012, Pengantar Sistem Informasi, Graha ilmu, Yogyakarta.

Andi dan Madcoms, 2013, kupas tuntas Adobe Dreamweaver Dengan Pemrograman PHP Dan MySQL, Andi Yogyakarta.

Arisandy, Muharto, dkk. 2016 Komputer : Merakit,Menginstal dan Menggunakan Microsoft Office Word, Deepublish, Yogyakarta.

Fitriastuti, Fatsyahrina, dkk. Aplikasi Sistem Pakar Berbasis Web untuk Mendeteksi Kerusakan Perangkat Keras Komputer Dengan Metode Backward Chaining. JANATEKNIKA Vol. 11 No. 2 : Juli 2009.

Ahmad Jamal, Sukadi, Rancang Bangun Sistem Pakar Diagnosa Kerusakan Notebook Pada Widodo Computer Ngadirojo Kabupaten Pacitan, Journal Speed - Sentra Penelitian Engineering dan Edukasi - ijns.org, Volume 7 No 3 - 2015, ISSN : 1979-9330 (Print) 2088 - 0154 (Online)

Siska Iriani, Penerapan Metode Backward Chaining pada Sistem Pakar Diagnosa Penyakit Tulang Manusia, IJNS Indonesian Journal on Networking and Security - Volume 4 No 1 - 2015, ISSN: 2302-5700 (Print) 2354-6654

(Online) 